(Aus dem thierphysiol. Laboratorium der landwirthschaftlichen Academie Poppelsdorf.)

\title{
In wiefern beeinflusstNahrungszufuhr die thierischen Oxydationsprocesse?
}

\author{
Vorläufige Mittheilung \\ von \\ Dr. V. Mexing und Prof. N. Zuntz.
}

Der thierische Stoffwechsel ist bekanntlich im Inanitionszustande geringer als bei normaler Nahrungszufuhr und ist durch überreiche Ernährung einer weiteren Steigerung fähig. Wir brauchen in dieser Hinsicht unter Anderen nur auf die Arbeiten von Bidder und Schmidt, sowie ron Pettenkofer und Voit hinzuweisen.

Man scheint allgemein anzunehmen, dass diese Steigerung des Stoffwechsels bedingt ist durch die Gegenwart der resorbirten Stoffe im Blute, während es doch ebensowohl möglich ist, dass die mit der Digestion und Resorption verbundene Arbeit des Darmcanals und seiner Drüsen die Steigerung des Stoffwechsels verursacht.

Einen Weg diese Alternative zu entscheiden hat Scheremetjewski eingeschlagen. Er spritzte Thieren Nahrungsstoffe ins Blut und untersuchte vorher und nachher deren Gaswechsel. Seine Resultate schienen der ersten der oben aufgestellten Alternativen günstig zu sein. Er fand bekanntlich, dass milchsaures und capronsaures Natron, sowie Glycerin Sauerstoffverbrauch und Kohlensäureexhalation steigern, während essigsaures, ameisensaures, benzoesaures Natron, Traubenzucker diesen Erfolg nicht hätten.

Unsere eigenen Versuche zerfallen in zwei Categorien: Messung des Gaswechsels vor und nach Einspritzung nährender Stoffe ins Blut einerseits, vor und nach Einführung in den. Magen andererseits. 
Wir experimentirten ausschliesslich an Kaninchen, die wir vorher, um sie fiir den Effect der Nahrungszufuhr empfindlicher zu machen, 1-3 Tage hungern liessen. Der Gaswechsel wurde mit Hülfe des von Röhrig and Zuntz angegebenen Respirationsapparates gemessen. An dem Apparate waren eine Anzahl zum Theil schon durch v. Platen und den Einen von uns beschriebener Verbesserungen angebracht. Die Thiere wurden während der ganzen Versuchsdaner in ein so warmes Bad versenkt, dass ihre Körpertemperatur normal und möglichst constant blieb.

Wenn so die Wärmeregulation ausgeschlossen ist, zeigt sich der Gaswechsel sehr gleichmässig.

Von den beiden zur Verfügung stehenden Apparaten wurde immer der eine mit Sauerstoff und Kalilauge beschickt, während das Thier an dem anderen athmete, so dass die Messung des Gaswechsels continuirlich beliebig lange fortgesetzt werden konnte. Die Umschaltung wurde fast momentan durch Schliessen einer einzigen Klemme und Oeffnen einer anderen bewirkt, wodurch die Athemmechanik gar keine Störung erfuhr. Meist wurde jede Viertelstunde umgeschaltet und der Sauerstoffrerbrauch sofort approximativ berechnet.

Nachdem wir uns dann durch eine Reihe von Bestimmungen von seiner Constanz überzengt hatten, wurde dem Thiere der Stoff, dessen Wirkung untersucht werden sollte, langsam in die Vena jugularis oder in den Magen gebracht. Um die Injection ohne jede Reizung und ohne Aufenthalt bewirken zu können, befand sich von Beginn des Versuchs an in der abgeklemmten Vena jugularis oder in dem Oesophagus die Injectionscanüle.

Unsere Versuche führten zu folgenden Resultaten:

1) Milchsaures Natron, fettsaures Natron, Glycerin, Zucker, direct ins Blut eingeführt, sind ohne Einfluss auf die Sauerstoffaufnahme ${ }^{1}$ ).

1) Die zum Theil von unseren Resultaten abweichenden Angaben Scheremetjewski's beruhen auf Fehlerquellen, von denen auch wir Anfangs getäuscht wurden. Wir werden hierauf in der ausführlichen Mittheilung näher eingehen. - Ueber das Verhalten der Kohlensäureausscheidung liegen uns noch nicht hinreichend Zahlen vor, und werden wir deshalb später darüber berichten. 
636 Dr. v. Mering u. Prof. N. Zuntz: Inwiefern beeinflusst Nahrungszufuhr etc.

2) Peptone, ins Blut injicirt, bewirken eine entsehiedene Steigerung der Sauerstoffaufnahme.

3) In den Magen gebracht, steigern nicht allein die Peptone, sondern auch die sub 1 genannten Stoffe die Sauerstoffaunahme.

4) AuchStoffe, welche unverändertden Thierkörper passiren, aber Peristaltik und Secretion anregen, (schwefelsaures Natron, Mannit), steigern rom Magen her den Sauerstoffverbrauch wesentlich ${ }^{\mathbf{1}}$ ).

Demnach bedingen unter den bisher untersuchten Stoffen durch ihr chemisches Verhalten im Organismus allein die Peptone, eine Steigerung des Sauerstoffverbrauchs, die übrigen nur indirect dadureh, dass siedie Thätigkeit des Darmcanals und seiner Drüsen anregen.

Um Missdeutungen vorzubeugen, sei hier ausdrïcklich hervorgehoben, dass wohl nicht bezweifelt werden kann, dass die sub 1 genannten. Stoffe im Organismus verbrannt werden. Die Grösse aber der Verbrennung im Thierkörper scheint, unabhängig von Vorrath und Zufuhr, sich allein nach dem jeweiligen Bedarf des Organismus zu richten. Nur die Assimilation der Peptone ist mit einem Mehrverbrauch an Sauerstofi nothwendig verknipft.

1) 3 grammes schwefelsaures Natron, in den Magen eingeführt, steigern den Sauerstoffverbrauch für eine Reihe von Stunden um 10-15\%. Mannit, welches bekanntlich unverändert durch den Urin wieder ausgeschieden wird, hat denselben Effect wie Traubenzucker. 3 grammes Traubenzucker steigerten den Sauerstoffrerbrauch um 7,2\%, 3 grammes Mannit um 7,8\%. 